\title{
Mesenchymal Stromal Cells and Fibroblasts
}

\section{Christine Ulrich ${ }^{1}$, Melanie L. Hart ${ }^{1,2}$, Bernd Rolauffs ${ }^{3}$, Harald Abele ${ }^{4}$, Marco Götze ${ }^{5}$, Karin Benz ${ }^{6}$ and Wilhelm K. Aicher ${ }^{1,5 *}$}

${ }^{1}$ Center for Regenerative Biology and Medicine, University of Tübingen, Germany

${ }^{2}$ Department of Anesthesiology and Intensive Care, University of Tübingen Hospital, Tübingen, Germany

${ }^{3} B G U$ Trauma Center, Tübingen, Germany

${ }^{4}$ Department of Obstetrics and Gynaecology, UKT, University of Tübingen Hospital, Tübingen, Germany

${ }^{5}$ Department of Orthopaedic Surgery, University of Tübingen Hospital, Tübingen, Germany

${ }^{6}$ Department of Cell Biology, Regenerative Medicine II, NMI at University of Tübingen, Reutlingen, Germany

\section{Summary}

Adult mesenchymal stromal cells (MSC), also referred to as mesenchymal stem cells, were detected almost half a century ago in bone marrow and have been studied intensively in the last decade. Different aspects of MSC biology were explored and published. Studies pointed to their localization in different organs during development and in adulthood and described their characteristics in experimental or clinical investigations. Despite intensive research in the field and in sharp contrast to hematopoietic stem cells (HSC), it has become more and more clear that MSC lack a unique cell surface marker. MSC not only share cell surface markers with other types of cells, they also share many features with pericytes and fibroblasts, including their capability to differentiate into, for instance, osteoblasts or adipocytes. In this review we therefore screen the current literature to disclose differences between MSC and fibroblasts and also report on common qualities.

\section{Introduction}

Almost 140 years ago, in 1876, changes in the appearance of bone marrow were associated with anemia suggesting that some blood cells might arise from this source [1]. In 1867 the same author, Prof. Cohnheim, had already reported that dye-labelled fibroblast-like cells migrated to sites of injury and inflammation during would healing processes [2]. He concluded that at least some of the invading cells involved in tissue regeneration might be derived from blood or bone marrow. Basically a century later, in 1966, Friedenstein described an osteogenic population of cells isolated originally from bone marrow [3] and several studies from Friedenstein's laboratory portrayed the cells, we call MSC today, in more detail [4-6]. Back then of course an in depth characterization of the expression of cell surface markers and discrimination between several distinct lines or types of MSC was impossible for a simple reason. The generation of monoclonal and highly specific antibodies to defined cell surface structures and proteins was developed in the seventies and published in 1975 [7]. In addition, in the first decade of research with this new tool, most monoclonal antibodies were generated to cells involved in immune responses or related to malfunction of the immune system. Therefore knowledge on hematopoietic stem cells (HSC), the expression of cell surface antigens on HSC or the many blood borne cells in association with differentiation pathways led the field of cellular research since. Even activation or inactivation of immune cells during inflammation and infection, in autoimmunity or in hematopoietic diseases can often be explored with monoclonal antibodies nowadays. This is different for MSC: Antibodies to isolate, characterize and possibly even separate MSC from their progeny, including fibroblasts, osteoblasts, chondrocytes, adipocytes and others or reagents to distinguish functional subsets within MSC preparations are not readily available.

But in recent years more and more studies generated a solid foundation that differentiation-competent MSC reside not only in bone marrow, but also in other tissues and MSC were isolated from different origins [8-10]. In 1999 the description of human bone marrow-derived MSC (bmMSC) expressing the antigens SH2 (CD105) and SH3 (CD73), but lack antigens characteristic for monocytes (CD14), HSC (CD34, CD133) or endothelial cells (CD31, CD34) and leukocytes (CD45) initiated an avalanche of studies and publications on this novel topic [11,12]. The differentiation capacity of MSC to generate osteoblasts, chondrocytes and adipocytes in vivo or in vitro [12] was corroborated by many studies. Some laboratories claimed an even wider differentiation capacity. Among others, generation of muscle cells [13], neuronal cells [14] and endothelial cells was described [15] But the overall efficacy of generating differentiated cells from MSC was and is very variable [16]. This may be due to several reasons:

i. The protocols for in vitro differentiation of MSC are suboptimal.

ii. During in vitro expansion MSC change or lose the original differentiation capacity [17].

iii. Bulk MSC contains distinct subsets of predetermined cells that preferably differentiate towards one cell line but not to any other type of cell [18].

iv. Efficient differentiation requires a complex blend of biological, chemical and physical stimuli, including:

a. Soluble signals (hormones, growth factors, low molecular weight compounds, $\mathrm{O}_{2}$ and NO-content, etc.).

b. Engagement of the cellular niche (extracellular matrix composition [19], integrin anchorage of cells, matrix nanopatterns, cell-cell interactions, etc.) [20].

c. Elasticity of the environment [21].

*Corresponding author: Wilhelm K Aicher, Center for Regenerative Medicine Deptarment of Orthopeadic Surg.ZMF, University of TübingenWaldhörnlstr. 2272072 Tübingen, Germany, Tel: +49 707129 86045; Fax: +49 707129 4637; E-mail: Aicher@uni-tuebingen.de

Received December 23, 2011; Accepted January 23, 2012; Published January 25, 2012

Citation: Ulrich C, Hart ML, Rolauffs B, Abele H, Götze M, et al. (2012) Mesenchymal Stromal Cells and Fibroblasts. J Tissue Sci Eng 3:e109. doi:10.4172/21577552.1000e109

Copyright: () 2012 Ulrich C, et al. This is an open-access article distributed under the terms of the Creative Commons Attribution License, which permits unrestricted use, distribution, and reproduction in any medium, provided the original author and source are credited. 
Thus, there is experimental evidence that all of the above contribute to MSC differentiation [18,22-24] (Figure 1). However, there is even one more important integral element to take into account: the source of MSC [25]. Cells sharing many features with MSC can be isolated from virtually all tissues even in adult donors [8]. Despite the similarities of the MSC derived from different origins, it has been noted that the differentiation capacity of MSC varies considerably among cells isolated from different sources $[25,26]$. To shed some light on the biology of MSC, consensus conferences coined some criteria to better define MSC from bone marrow (bmMSC) $[27,28]$ or placenta (pMSC) $[29,30]$. But an in-depth methodical examination to define MSC from adipose (aMSC) [31] or other tissues was not presented [8,25,3234]. Although the differences between MSC from different sources constitute an interesting field for research and reflection, in this review we discuss expression of cell surface markers to discriminate MSC from other cells and address the problems and recent studies of multilineage differentiation of both MSC and dermal fibroblasts (DF).

\section{Differences in gene expression}

To discriminate human DF from human bmMSC, gene expression analyses have been performed [35]. In these studies all known transcripts of the whole human genome were investigated by a microarray technique allowing an in-depth screening of the gene expression of a given sample. The authors report that 64 genes defined the molecular signature of MSC in comparison to fibroblasts. All gender-related genes were eliminated and a minimum of a 10-fold difference in steady-state transcript levels between DF and bmMSC was applied [35]. Statistical evaluation of replications of sets of probes indicated that the reproducibility was satisfactory (i.e. $p$ 0.065). Interestingly, many of the transcripts that were expressed differently

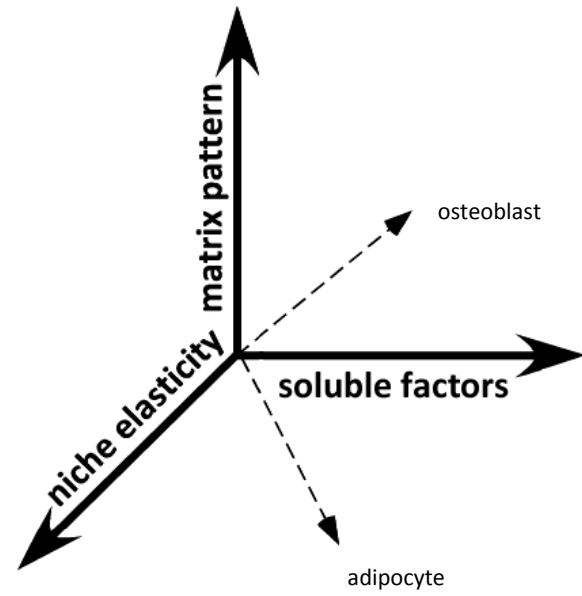

Figure 1: Stimuli inducing and modulating the differentiation of mesenchymal stromal cells. MSC reside in niches and their proliferation and differentiation is regulated by $(x)$ soluble factors, including cytokines, hormones, growth factors, and low molecular weight components, by $(y)$ the extracellular matrix, its composition and cell-cell interactions, and by (z) the elasticity of the niche. The osteogenic differentiation is for instance facilitated in a less elastic, rigid environment, in combination with collagen signalling, and appropriate cytokines (upper dotted pathway). In a soft, more elastic environment, soluble factors and matrix signals will rather generate adipocytes (lower dotted pathway) [21]. However, it seems that the general direction of differentiation is set by the soluble factors, and that the extracellular matrix and elasticity of the niche modulate the efficacy of differentiation. in DF vs. bmMSC coded for cell membrane proteins. Among them the plexin domain-containing protein 1 (PLXDC1, expression ratio MSC $>\mathrm{DH}, 37$-fold), also referred to as tumor endothelial marker 7 (TEM7). PLXDC1 plays an important role in generation of neovasculature and it molds capillary morphogenesis. It is associated with high risk of metastases and poor prognosis in patients with osteosarcoma. Another membrane protein, $\mathrm{N}$-acetylgalactosaminyl-transferase 3 (GALNT3, expression ratio MSC > DH, 30-fold), is an enzyme involved in oligosaccharide biosynthesis. Mutations of GALNT3 have been associated with pathology in mineralization of bone, high risk of bone fracture and even mineral deposition in soft tissues (calcinosis). Another interesting factor reported to be expressed differently is vascular cell adhesion molecule 1 (VCAM1, expression ratio MSC $>$ DF, 20-fold) [35]. VCAM1 was given the cluster of differentiation (CD) CD106 and in another study a 6-fold higher mRNA expression was observed in MSC in early passages [36]. CD106 is expressed by endothelial cells in both, large and small blood vessels. It mediates the interaction between the vessel wall and different cells and is the principle ligand to integrin $\alpha 4 \beta 1$ or $\alpha 4 \beta 7$. Expression of CD106 was reported on MSC from bone marrow [18], placenta [37], but not on MSC from adipose tissue [38]. CD106 is normally not expressed on DF [39]. Therefore prima vista expression of CD106 seems to discriminate between MSC and fibroblasts. We will inspect this hypothesis in the next chapter, when we elaborate differences between MSC and DF with regard to expression of cell surface proteins.

In addition, fibroblast growth factor receptor 2 (FGFR2, CD332) and vascular endothelial growth factor A (VEGFA) were both expressed in MSC approximately 10-fold higher compared to DF [35]. FGFR2 was associated with regulation of osteogenesis. Therefore an elevated expression of FGFR2 on bmMSC is not surprising. Regulation of VEGFA is activated in MSC by low oxygen tension [40] and hypoxia was shown to facilitate its expression in fibroblasts as well [41]. Hence this factor is also not a prime candidate to discriminate DF from MSC.

Expression of transcripts encoding the alpha-11 chain of integrin (7-fold) and integrin-like growth factor-2 were also elevated (5fold) in early passage MSC compared to DF. In contrast, expression of interstitial collagenase (MMP1) and stromelysin (MMP3) were elevated 8-and 6-fold in DF compared to MSC, respectively [36].

Regrettably, the studies investigating the transcriptome in MSC vs. DF $[35,36,42]$ utilized cells from commercial sources. So the term "early passage" has to be put in perspective to the history of the individual batch of MSC. Thus, the number of cell divisions prior to the actual experiment may vary. Moreover, expansion media and other variables influence the outcome of the studies as well. Therefore determination of differences between MSC and DF should possibly be standardized by defining variances and consistencies between MSC and DF ex vivo. Here of course, monoclonal antibodies enter the stage. But isolating MSC and especially DF from tissue puts stress on the cell and generally involves proteolytic enzymes at some stage. Note that even mild proteolysis may harm structures on cell surfaces. Thus, this strategy of ex vivo characterization of MSC versus DF has its disadvantages as well.

\section{Surface markers of MSC and fibroblasts}

As pointed out above, investigation of the whole transcriptome on human MSC and DF to determine differences between these cell types is a very interesting scientific challenge, at least scholarly [35]. For practical purposes and especially for tissue engineering in a pre-clinical or clinical setting, a clear-cut discrimination or even separation of MSC 
from fibroblasts, osteoblasts, adipocytes by a cell surface determinant would improve our proposition.

According to consensus conferences [27,28,30], bmMSC express CD73, CD90, CD105 and lack expression of antigens found on monocytes (CD11b, CD14), on HSC (CD34, CD133), endothelial cells (CD31, CD133) or on leukocytes (CD45). The bmMSC also lack expression of the major histocompatibility antigens HLA class II. However, this pattern of expression of cell surface antigens $\left(\mathrm{CD}^{+} 3^{+}\right.$, $\left.\mathrm{CD}^{+} 0^{+}, \mathrm{CD}_{105}{ }^{+}, \mathrm{CD} 11 \mathrm{~b}, \mathrm{CD} 144^{-} \mathrm{CD} 31^{\circ}, \mathrm{CD} 344^{-} \mathrm{CD} 45^{-}, \mathrm{HLAclassII}\right)$ was observed with DF too. But there seems to be at last distinct patterns of antigen expression discriminating e.g. bmMSC ex vivo (CD271 TNAP ${ }^{+}$, SSEA-4, TRA-1-81- ) [22-24] from other MSC or from DF. For instance, adipose tissue-derived MSC express ex vivo and in early passages of in vitro cultures CD34 but lack expression of CD271 [43], whereas MSC from the amnion membrane express SSEA-4 and TRA1-81, but not CD271 [44, 45]. Therefore expression of CD271, TNAP, SSEA-4, TRA-1-81, or CD34 can be utilized to at least discriminate DF from some MSC ex vivo.

As outlined in the previous paragraph, expression of CD106, alias VCAM1, encoding mRNA was significantly different in MSC compared to DF [35]. But determination of CD106 by flow cytometry reports that only $2 \%$ of bmMSC and $10 \%$ of pMSC express CD106 on the cellular surface [46]. On normal DF, CD106 is not detected by flow cytometry. But it can be activated by different stimuli [47]. Furthermore, on MSC expression of CD106 is fading in vitro [36]. So on MSC its expression depends on the culture conditions. Thus despite significant differences in mRNA expression rates of CD106 between MSC and DF [36], expression of the CD106 protein varies on both MSC and DF depending on culture conditions. In addition, DF was shown to be differentiation competent [48]. Therefore expression of CD106 is not a robust marker to discriminate MSC from fibroblasts.

Recently, fibroblast-activation protein alpha (FAPa) was reported to be expressed on bmMSC but not on other bone marrow-derived cells [49]. But spontaneous expression of FAPa was rather high in normal human DF, although the mean of fluorescence intensity was further increased significantly in keloid DF from scar tissue [50]. Therefore, as stated for CD106, FAPa seems not to be a feasible marker for discriminating MSC from fibroblasts.

Moreover, expression of CD146 was observed on bmMSC, but not on DF, osteoblasts, periosteal cells, nor on cells derived from fibrotic bone marrow [51]. This suggested that CD146 might serve as marker to discriminate MSC form DF. We corroborated that bmMSC express CD146 and CD146 was observed on bmMSC at higher levels compared to pMSC [26]. But our preliminary studies indicate that DF expresses CD146 at levels close to pMSC, at least when expanded in the same medium as the MSC (Ulrich, doctoral thesis, EberhardKarls-University, Tübingen, Germany (in preparation)). A current compendium on expression of MSC cell surface markers concluded that there is great discrepancy in the literature [52]. For science these inconsistencies are a challenge tempting our curiosity and therefore academic sport. For colleagues involved in tissue engineering and production of MSC for therapeutic regimen, lack of clear MSC markers become a difficult problem.

\section{Differences in expression of small RNA species}

In addition to investigating differences in steady state amounts of mRNA between MSC and DF [35,36], differences were also explored in the pools of microRNA's (miRNA) [35]. In contrast to the mRNA, which is a complex population of messengers encoding all proteins required for proper metabolism, miRNA are non-coding short molecules ( \pm 22 nucleotides) that regulate the biological activity of mRNA by binding to the 3' untranslated regions, thus either blocking translation or facilitating the degradation of the respective target mRNA. Current knowledge suggests that miRNA's are expressed in tissue-specific manner. Thus differences in miRNA signature were found for miRNA-335 (ratio bmMSC vs. DF, 44-fold). Thus measuring miRNA-335 in cells may help for quality control of bmMSC. It remains to be determined if the expression of miRNA's may help to discriminate DF from MSC of different sources including adipose tissue, peripheral blood, placenta, amnion membrane, etc. This is of importance as MSC maintain a gene expression signature depending on the positioning of their precursor cells in the anlagen during embryonic development [53]. This miRNA-335 binds to the mRNA encoding a hydrolase named MEST or PEG1. Dysregulation of MEST/PEG1 was found in cancer cells and genetic deletion of miRNA-335 is very common in breast cancer [54].

\section{Raman Spectroscopy for non-contact discrimination of cells}

Very recently, a promising study pioneered a novel method to discriminate even closely related but still different types of cells: Raman spectroscopy [55]. Hereby, live cells are activated via a high-power infrared laser beam. The laser photons interact with molecules and lift them on high-energy states. When the molecule relaxes it emits photons in any direction (scatter), which are detected by sensitive photomultipliers or CCD cameras. The intensity and wavelength of scattered light is measured. The Raman spectroscopy proved to be a very sensitive method as 20 -30 cells per analysis were sufficient to generate a spectrum $[55,56]$. In addition, a single measurement took less than 2 minutes for data acquisition and did not require time-consuming preparations beforehand. Flow cytometry for instance requires several steps in preparation of the data acquisition: incubation of cells with antibodies, washing and possibly even addition of detection reagents. For characterization of MSC we routinely stain $1 \times 10^{5}$ cells and acquire data from $5 \times 10^{4}$ events. In addition, MSC stained with antibodies often can't be immediately processed for a clinical application. Therefore additional steps for removal of antibodies have to be added when MSC will be applied to humans after flow cytometry or fluorescence activated cell sort (FACS). In contrast, Raman spectroscopy does not require any manipulation of the cells to be investigated and, as far as we can say today, the infrared laser-based methods seem not to harm cells.

The Raman spectra have also been utilized to investigate live cells in tissues [55]. This technique therefore may allow monitoring of behavior of MSC in situ during wound healing. Right now we are still at the beginning of this development. Therefore we are convinced that this Raman technique will soon cross the threshold in the field of regenerative medicine and tissue engineering.

\section{Stemness of MSC}

The above mentioned experts in grand rounds [30] and consensus conferences $[27,28]$ stated that the triple lineage differentiation potential of MSC was an important hallmark to better define the fibroblast-like MSC. MSC was the acronym for mesenchymal stem cells [28]. The terminus "stem cell" is in use for unspecialized cells that can differentiate into more specialized cells of one type or several types or lineages. A stem cell replaces cells that die or are lost in the body and retains lifelong proliferation and self-renewal. In bona fide MSC expression of factors characteristic "stemness", i.e. cell proliferation and differentiation such as IGF1, IGFBP4, AKT3, STAT1, STAT4, 
SMAD3, FZD7, DKK3 were detected [57]. At the same time these cells proliferated well in vitro. But this concept of a stem cell maintaining full "stemness" at continuous proliferation is not supported by investigation of the hematopoietic stem cell niche and HSC therein [9]. The true hematopoietic stem cell (HSC) divides in situ very slowly, but expresses telomerase at high levels to keep the chromosomal ends complete [58] (see below). From this slow proliferating true HSC, rapidly dividing progenitor cells are derived which have already lost the full potential of the HSC. In vitro a slow proliferating stem cell will be lost between the proliferating progenitors cells, unless we utilize a reagent, antibody, ligand, feeder cell, or any tool to first select the stem cell specifically and then maintain this cell in culture, if possible as a true clone. Such a tool, reagent, antibody or alike will be beneficial in discriminating MSC or even subsets of MSC from DF. It also will be helpful to better localize the true MSC in its niche or niches in vivo. It also may help to define MSC satisfactorily for authorities \{e.g., EMA (www.ema.europa. eu), FDA (www.fda.gov) $\}$ involved in approval of cell-based therapies.

In contrast to true stem cells, proliferating MSC display signs of senescence after repeated rounds of passaging in vitro and fail to express telomerase at substantial levels [59-61]. Furthermore, clones of permanent cells lines reportedly developed from MSC after long term expansion [62]. But they were shown to be contaminants overgrowing the original MSC population, at least in some cases [63].

Another problem with the concept of "stemness" of MSC is observed with regard to the differentiation potential. MSC from different sources display a distinct differentiation potential. For instance, placentaderived MSC do not generate osteoblasts efficiently in vitro [26] and umbilical cord-derived MSC will not become adipocytes effectively [64]. Others reported a preferential chondrogenic differentiation potential in MSC derived from synovial membranes [65], but a more detailed study revealed later that the in vitro chondrogenically differentiated MSC failed to generate a stable cartilage tissue at ectopic sites [66]. Therefore the differentiation potential of MSCs depends very much on the source of cells and the experimental conditions as well. Here, therefore, the aforementioned position signature of MSC may come into play [53]. Moreover, MSC change their differentiation potential in vitro [17]. Therefore an important criterion to name a cell stem cell is not really fulfilled by MSC: long-term self-renewal and full differentiation competence at the same time. Consequently at the present time the term mesenchymal stromal cell is preferred.

On the other side, fibroblasts were shown to have a differentiation potential and generation of adipocytes, chondrocytes and osteoblasts $[48,67]$ or adipocytes and osteoblasts [68] was induced from human $\mathrm{DF}(\mathrm{hDF})$. Moreover, both populations, the adipose tissue-derived MSC and the DF expressed factors found in embryonic stem cells [52] and hDF seem to express KLF4 at high levels compared to MSC [67]. Therefore it seems that hDF share expression of many cell surface proteins with MSC, including the markers commonly utilized for MSC characterization [27]. In addition, hDF display a tri-lineage differentiation potential and are capable of generating colonies in vitro $[48,67,68]$. Although MSC and DF were studied intensively with cells from a variety of species, the differences between these two types of cells are not yet fully evident.

\section{Conclusion}

At present, a simple guide as how to best discriminate human mesenchymal stromal cells derived from bone marrow, adipose or other tissues from human dermal fibroblasts or fibroblast harvested from other source is not at hand. To name a cell a MSC, it must fulfill the inclusion criteria $[27,28,30]$ and maintain a differentiation potential at least for a few cycles of cell division during expansion in vitro. But fibroblasts share many features with "true" MSC, including a basic differentiation capacity.

Note that the limited differentiation capacity of some fibroblasts or some MSC will be advantageous in a given clinical context: A prominent osteogenic differentiation for instance and deposition of a calcified extracellular matrix by bmMSC is cumbersome when soft tissue such as adipose or muscular tissue needs regeneration or repair. In this context autologous dermal fibroblast or placenta-derived MSC yield advantages. In the end, the definitive discrimination between MSC and fibroblasts seems to be a purely academic matter. It seems more important what a given cell will do in vitro or in vivo and for which particular experimental or clinical need a given cell really is the best component. But in the context of regenerative medicine and for cell-based therapies, a defined tool to discriminate MSC from other cells would be of tremendous progress. We therefore entertain in our laboratory studies investigations using both MSC and DF and utilize cells from different niches or tissues, expand the cells under conditions compatible to the standards required for clinical application (i.e., good medical procedures, GMP) in order to find the best type of cell for a given purpose.

\section{Acknowledgements}

The authors own great gratitude to Tanja Abruzzese, Elisabeth Kienzle and Stephanie Zug for their excellent technical support, Hans J. Bühring for specific monoclonal antibodies to characterize MSC. Our work was supported in part by grants to WKA (DFG Ai16/19; BMBF 313755, 01QK0902A; Landesstiftung BW 22-005-2009), to BR (DGUV \# 148), to MLH (fortüne 1783-0-0), by the ZRM at University of Tübingen and in part by Institutional funding.

\section{References}

1. Cohnheim J (1876) Erkrankung des Knochenmarkes bei perniciöser Anämie Virchows Archiv Volume 68: 291-293.

2. Cohnheim J (1867) Über Entzündungund Eiterung. Arch Path Anat Physiol Klin Med 40: 1-79.

3. Friedenstein AJ, Piatetzky-Shapiro II, Petrakova KV (1966) Osteogenesis in transplants of bone marrow cells. J Embryol Exp Morphol 16: 381-390.

4. Friedenstein AJ, Chailakhyan RK, Gerasimov UV (1987) Bone marrow osteogenic stem cells: in vitro cultivation and transplantation in diffusion chambers. Cell Tissue Kinet 20: 263-272.

5. Friedenstein AJ, Deriglasova UF, Kulagina NN, Panasuk AF, Rudakowa SF et al. (1974) Precursors for fibroblasts in different populations of hematopoietic cells as detected by the in vitro colony assay method. Exp Hematol 2: 83-92.

6. Friedenstein AJ, Gorskaja JF, Kulagina NN (1976) Fibroblast precursors in normal and irradiated mouse hematopoietic organs. Exp Hematol 4: 267-274.

7. Köhler G, Milstein C (1975) Continuous cultures of fused cells secreting antibody of predefined specificity. Nature 256: 495-497.

8. da Silva Meirelles L, Chagastelles PC, Nardi NB (2006) Mesenchymal stem cells reside in virtually all post-natal organs and tissues. J Cell Sci 1: 22042213.

9. Wilson A, Trumpp A (2006) Bone-marrow haematopoietic-stem-cell niches Nature Reviews Immunology 6: 93-106.

10. Mendes SC, Robin C, Dzierzak E (2005) Mesenchymal progenitor cells localize within hematopoietic sites throughout ontogeny. Development 132: 1127-1136.

11. Pittenger MF, Mackay AM, Beck SC, Jaiswal RK, Douglas R, et al. (1999) Multilineage potential of adult human mesenchymal stem cells. Science 284 143-147.

12. Pittenger MF, Mosca JD, Mclntosh KR (200) Human mesenchymal stem cells: progenitor cells for cartilage, bone, fat and stroma. Curr Top Microbiol Immuno 251: 3-11.

13. Wakitani S, Saito T, Caplan Al (1995) Myogenic cells derived from rat bone 
Citation: Ulrich C, Hart ML, Rolauffs B, Abele H, Götze M, et al. (2012) Mesenchymal Stromal Cells and Fibroblasts. J Tissue Sci Eng 3:e109. doi:10.4172/2157-7552.1000e109

Page 5 of 6

marrow mesenchymal stem cells exposed to 5-azacytidine. Muscle Nerve 18: 1417-1426.

14. Qian L, Saltzman WM (2004) Improving the expansion and neurona differentiation of mesenchymal stem cells through culture surface modification. Biomaterials 25: 1331-1337.

15. Liu JW, Dunoyer-Geindre S, Serre-Beinier V, Mai G, Lambert JF, et al. (2007) Characterization of endothelial-like cells derived from human mesenchymal stem cells. J Thromb Haemost 5: 826-834.

16. Aicher WK, Bühring HJ, Hart M, Rolauffs B, Badke A, et al. (2011) Regeneration of cartilage and bone by defined subsets of mesenchymal stromal cells-potential and pitfalls. Adv Drug Deliv Rev 63: 342-351.

17. Muraglia A, Cancedda R, Quarto R (2000) Clonal mesenchymal progenitors from human bone marrow differentiate in vitro according to a hierarchical mode. J Cell Sci 113: 1161-1166.

18. Battula VL, Treml S, Bareiss PM, Gieseke F, Roelofs H, et al. (2009) Isolation of functionally distinct mesenchymal stem cell subsets using antibodies agains CD56, CD271, and mesenchymal stem cell antigen-1. Haematologica 94: 173184

19. Klees RF, Salasznyk RM, Ward DF, Crone DE, Williams WA, et al. (2008) Dissection of the osteogenic effects of laminin-332 utilizing specific LG domains: LG3 induces osteogenic differentiation, but not mineralization. Exp Cell Res 314: 763-773.

20. McNamara LE, McMurray RJ, Biggs MJ, Kantawong F, Oreffo RO, et al. (2010) Nanotopographical control of stem cell differentiation. J Tissue Eng 2010: 120623.

21. Engler AJ, Sen S, Sweeney HL, Discher DE (2006) Matrix elasticity directs stem cell lineage specification. Cell 126: 677-689.

22. Bühring HJ, Battula VL, TremI S, Schewe B, Kanz L, et al. (2007) Novel markers for the prospective isolation of human MSC. Ann N Y Acad Sci 1106: 262-267.

23. Bühring HJ, Treml S, Cerabona F, de Zwart P, Kanz L, et al. (2009) Phenotypic characterization of distinct human bone marrow-derived MSC subsets. Ann N Y Acad Sci 1176: 124-134.

24. Vogel W, Grünebach F, Messam CA, Kanz L, Brugger W, et al. (2003) Heterogeneity among human bone marrow-derived mesenchymal stem cells and neural progenitor cells. Haematologica 88: 126-333.

25. Limbert C, Ebert R, Schilling T, Path G, Benisch P, et al. (2010) Functional signature of human islet-derived precursor cells compared to bone marrowderived mesenchymal stem cells. Stem Cells Dev 19: 679-691.

26. Pilz GA, Ulrich $C$, Ruh $M$, Abele $H$, Schäfer R, et al. (2011) Human term placenta-derived mesenchymal stromal cells are less prone to osteogenic differentiation than bone marrow-derived mesenchymal stromal cells. Stem Cells Dev 20: 635-646.

27. Dominici M, Le Blanc K, Mueller I, Slaper-Cortenbach I, Marini F, et al. (2006) Minimal criteria for defining multipotent mesenchymal stromal cells. The International Society for Cellular Therapy position statement. Cytotherapy 8: 315-317.

28. Horwitz EM, Le Blanc K, Dominici M, Mueller I, Slaper-Cortenbach I, et al (2005) Clarification of the nomenclature for MSC: The International Society for Cellular Therapy position statement. Cytotherapy 7: 393-395.

29. Parolini O, Alviano F, Bergwerf I, Boraschi D, De Bari C, et al. (2010) Toward cell therapy using placenta-derived cells: disease mechanisms, cell biology, preclinical studies, and regulatory aspects at the round table. Stem Cells Dev 19: $143-154$

30. Parolini O, Alviano F, Bagnara GP, Bilic G, Bühring HJ, et al. (2008) Concise review: isolation and characterization of cells from human term placenta: outcome of the first international Workshop on Placenta Derived Stem Cells. Stem Cells 26: 300-311.

31. Zuk PA, Zhu M, Mizuno H, Huang J, Futrell JW, et al. (2001) Multilineage cells from human adipose tissue: implications for cell-based therapies. Tissue Eng 7: 211-228.

32. In't Anker PS, Scherjon SA, Kleijburg-van der Keur C, de Groot-Swings GM, Claas FH, et al. (2004) Isolation of mesenchymal stem cells of fetal or maternal origin from human placenta. Stem Cells 22: 1338-1345.

33. De Bari C, Dell'Accio F, Karystinou A, Guillot PV, Fisk NM, et al. (2008) A biomarker-based mathematical model to predict bone-forming potency of human synovial and periosteal mesenchymal stem cells. Arthritis Rheum 58 240-250.

34. Suzdal'tseva YG, Burunova VV, Vakhrushev IV, Yarygin VN, Yarygin KN (2007) Capability of human mesenchymal cells isolated from different sources to differentiation into tissues of mesodermal origin. Bull Exp Biol Med 143: 114 121.

35. Bae S, Ahn JH, Park CW, Son HK, Kim KS, et al. (2009) Gene and microRNA expression signatures of human mesenchymal stromal cells in comparison to fibroblasts. Cell Tissue Res 335: 565-573.

36. Halfon S, Abramov N, Grinblat B, Ginis I(2011) Markers distinguishing mesenchymal stem cells from fibroblasts are downregulated with passaging. Stem Cells Dev 20: 53-66.

37. Castrechini NM, Murthi P, Gude NM, Erwich JJ, Gronthos S, et al. (2010) Mesenchymal stem cells in human placental chorionic villi reside in a vascular Niche. Placenta 3: 203-212.

38. De Ugarte DA, Alfonso Z, Zuk PA, Elbarbary A, Zhu M, et al. (2003) Differential expression of stem cell mobilization-associated molecules on multi-lineage cells from adipose tissue and bone marrow. Immunol Lett 89: 267-270.

39. Gao JX, Issekutz AC (1996) Expression of VCAM-1 and VLA-4 dependent T-lymphocyte adhesion to dermal fibroblasts stimulated with proinflammatory cytokines. Immunology 89: 375-383.

40. Mayer H, Bertram H, Lindenmaier W, Korff T, Weber H, et al. (2005) Vascular endothelial growth factor (VEGF-A) expression in human mesenchymal stem cells: autocrine and paracrine role on osteoblastic and endothelia differentiation. J Cell Biochem 95: 827-839.

41. Steinbrech DS, Longaker MT, Mehrara BJ, Saadeh PB, Chin GS, et al. (1999) Fibroblast response to hypoxia: the relationship between angiogenesis and matrix regulation. J Surg Res 84: 127-133.

42. Bab I, Ashton BA, Gazit D, Marx G, Williamson MC, et al. (1986) Kinetics and differentiation of marrow stromal cells in diffusion chambers in vivo. J Cell Sci 84: 139-151.

43. Mitchell JB, McIntosh K, Zvonic S, Garrett S, Floyd ZE, et al. (2006) Immunophenotype of human adipose-derived cells: temporal changes in stromal-associated and stem cell-associated markers. Stem Cells 24: 376-385

44. Battula VL, Bareiss PM, Treml S, Conrad S, Albert I, et al. (2007) Human placenta and bone marrow derived MSC cultured in serum-free, b-FGFcontaining medium express cell surface frizzled-9 and SSEA-4 and give rise to multilineage differentiation. Differentiation 75: 279-291.

45. Yen BL, Huang HI, Chien CC, Jui HY, Ko BS, et al. (2005) Isolation of multipotent cells from human term placenta. Stem Cells 23: 3-9.

46. Miao Z, Jin J, Chen L, Zhu J, Huang W, et al. (2006) Isolation of mesenchymal stem cells from human placenta: comparison with human bone marrow mesenchymal stem cells. Cell Biol Int 30: 681-687.

47. Yellin MJ, Winikoff S, Fortune SM, Baum D, Crow MK, et al. (1995) Ligation of CD40 on fibroblasts induces CD54 (ICAM-1) and CD106 (VCAM-1) upregulation and IL-6 production and proliferation. J Leukoc Biol 209-216.

48. Junker JP, Sommar P, Skog M, Johnson H, Kratz G (2010) Adipogenic chondrogenic and osteogenic differentiation of clonally derived human dermal fibroblasts. Cells Tissues Organs 191: 105-118.

49. Bae S, Park CW, Son HK, Ju HK, Paik D, et al. (2008) Fibroblast activation protein alpha identifies mesenchymal stromal cells from human bone marrow. $\mathrm{Br} \mathrm{J}$ Haematol 142: 827-830.

50. Dienus K, Bayat A, Gilmore BF, Seifert O (2010) Increased expression of fibroblast activation protein-alpha in keloid fibroblasts: implications for development of a novel treatment option. Arch Dermatol Res 302: 725-731.

51. Sacchetti B, Funari A, Michienzi S, Di Cesare S, Piersanti S, et al. (2007) Self-renewing osteoprogenitors in bone marrow sinusoids can organize a hematopoietic microenvironment. Cell 131: 324-336.

52. Mafi R, Hindocha S, Mafi P, Griffin M, Khan WS (2011) Sources of adult mesenchymal stem cells applicable for musculoskeletal applications - a systematic review of the literature. Open Orthop J 2: 242-248.

53. Limbert C, Ebert R, Schilling T, Path G, Benisch P, et al. (2010) Functiona signature of human islet-derived precursor cells compared to bone marrowderived mesenchymal stem cells. Stem Cells Dev 19: 679-691. 
Citation: Ulrich C, Hart ML, Rolauffs B, Abele H, Götze M, et al. (2012) Mesenchymal Stromal Cells and Fibroblasts. J Tissue Sci Eng 3:e109. doi:10.4172/2157-7552.1000e109

Page 6 of 6

54. Png KJ, Yoshida M, Zhang XH, Shu W, Lee H, et al. (2011) MicroRNA-335 inhibits tumor reinitiation and is silenced through genetic and epigenetic mechanisms in human breast cancer. Genes Dev 1: 226-231.

55. Pudlas M, Koch S, Bolwien C, Thude S, Jenne N, et al. (2011) Raman spectroscopy: a noninvasive analysis tool for the discrimination of human skin cells. Tissue Eng Part C Methods 17: 1027-1040.

56. Pudlas M, Koch S, Bolwien C, Walles H (2010) Raman spectroscopy as a too for quality and sterility analysis for tissue engineering applications like cartilage transplants. Int J Artif Organs 33: 228-237.

57. Song L, Webb NE, Song Y, Tuan RS (2006) Identification and functional analysis of candidate genes regulating mesenchymal stem cell self-renewal and multipotency. Stem Cells 24: 1707-1718.

58. Wilson A, Murphy MJ, Oskarsson T, Kaloulis K, Bettess MD, et al. (2004) c-Myc controls the balance between hematopoietic stem cell self-renewal and differentiation. Stem Cells 24: 1707-1718.

59. Bernardo ME, Zaffaroni N, Novara F, Cometa AM, Avanzini MA, et al. (2007) Human bone marrow derived mesenchymal stem cells do not undergo transformation after long-term in vitro culture and do not exhibit telomere maintenance mechanisms. Cancer Res 67: 9142-9149.

60. Bruder SP, Jaiswal N, Haynesworth SE (1997) Growth kinetics, self-renewal and the osteogenic potential of purified human mesenchymal stem cells during extensive subcultivation and following cryopreservation. J Cell Biochem 64 278-294.

61. Bieback K, Kern S, Klüter H, Eichler H (2004) Critical parameters for the isolation of mesenchymal stem cells from umbilical cord blood. Stem Cells 22 625-634.

62. Røsland GV, Svendsen A, Torsvik A, Sobala E, McCormack E, et al. (2009) Long-term cultures of bone marrow-derived human mesenchymal stem cells frequently undergo spontaneous malignant transformation. Cancer Res 69: 5331-5339.

63. Torsvik A, Røsland GV, Svendsen A, Molven A, Immervoll H, et al. (2010) Spontaneous malignant transformation of human mesenchymal stem cells reflects cross-contamination: putting the research field on track - letter. Cancer Res 70: 6393-6396.

64. Kern S, Eichler H, Stoeve J, Klüter H, Bieback K (2006) Comparative analysis of mesenchymal stem cells from bone marrow, umbilical cord blood, or adipose tissue. Stem Cells 24: 1294-1301.

65. De Bari C, Dell'Accio F, Tylzanowski P, Luyten FP (2001) Multipotent mesenchymal stem cells from adult human synovial membrane. Arthritis Rheum 44: 1928-1942.

66. De Bari C, Dell'Accio F, Luyten FP (2004) Failure of in vitro-differentiated mesenchymal stem cells from the synovial membrane to form ectopic stable cartilage in vivo. Arthritis Rheum 50: 142-150.

67. Alt E, Yan Y, Gehmert S, Song YH, Altman A, et al. (2011) Fibroblasts share mesenchymal phenotypes with stem cells, but lack their differentiation and colony-forming potential. Biol Cell 103: 197-208

68. Lorenz K, Sicker M, Schmelzer E, Rupf T, Salvetter J, et al. (2008) Multilineage differentiation potential of human dermal skin-derived fibroblasts. Exp Dermato 17: $925-932$. 